following year on a short expedition to observe whether riboflavin deficiency was related to snow blindness among the Canadian Inuit. It is reported that he failed to keep any written record in his diaries but embellished the tale in later life to suggest that he had joined the expedition because he was interested in the fact that the Inuit diet was high in fat, rich in essential fatty acids, and yet the Inuit were free from heart disease. During this period of his life, Sinclair's work was concerned with thiamine and diseases of the nervous system, and there was no evidence of his having any interest in cardiovascular disease and dietary fat. His epic letter to the Lancet in 1956, in which he suggested that cardiovascular disease was caused by a deficiency of essential fatty acids, was an important stimulus to future research.

But Sinclair was blinkered by the deficiency paradigm. And the book perpetuates the myth that he was responsible for drawing attention to the cardioprotective properties of omega- 3 fatty acids. What he failed to note was that the balance of omega- 6 to omega- 3 fatty acids was important to health. Indeed, for many years he promoted the consumption of a diet high in omega- 6 fatty acids. The major impetus for cardiovascular research on the omega-3 fatty acids arose from the work of Salvador Moncada and John Vane on prostacyclin, and Philip Needleman on thromboxane, published in 1976, three years before Sinclair embarked on his Eskimo diet to demonstrate the effects of omega-3 fatty acids from fish oils on haemostasis.

Sinclair's life-long ambition was to establish a department of nutrition at Oxford. He was appointed reader in human nutrition there in 1951. There is little doubt that he was an able scholar, but his ability as a research scientist is questionable because of his lack of attention to detail and failure to publish his results in peer-reviewed journals. He was a prolific letter-writer and collector of manuscripts (including a collection of erotica) and, following his death, these sold for more

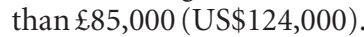

Like a few other famous nutritionists, such as Boyd Orr and Robert McCarrison, Sinclair liked to dabble in the politics of food and influence national policy. But his outpourings tended to be based on belief and theory rather than evidence and he was openly contemptuous of the work of his contemporaries, such as John Yudkin and Elsie Widdowson. But to his credit, Sinclair truly understood the complexity of the relationship between diet and health and recognized the need for a multidisciplinary approach.

As a scientist, he came to be regarded as a dilettante; his research lacked focus and was unsystematic. This, coupled with his failure to complete projects and produce peer-reviewed publications, and his sniping at influential contemporaries, eventually resulted in his ejection from Oxford's Department of Biochemistry in 1956 by Sir Hans Krebs, and his

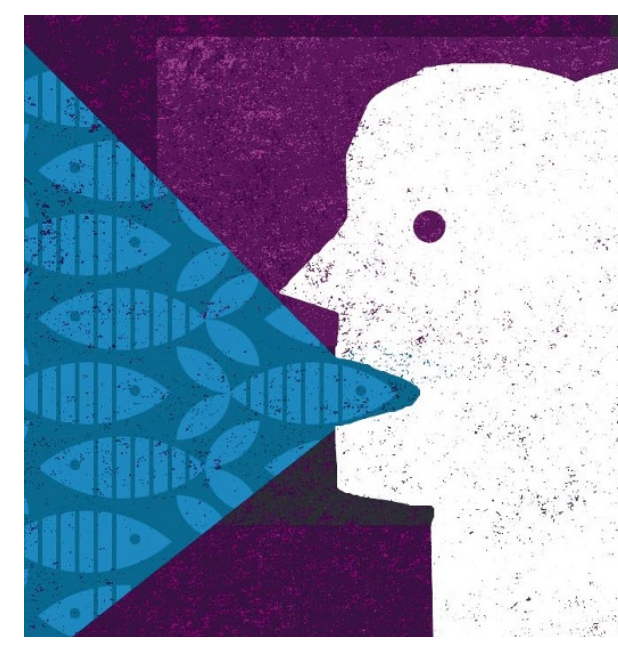

readership was not renewed in 1958. For the rest of his working life, Sinclair remained in the wilderness of his self-styled National Institute of Nutrition, which was situated in the grounds of his home at Lady Place in Sutton Courtenay. On his death, he bequeathed his estate to establish a chair in nutrition at Oxford which the university declined. The offer was eventually taken up by the University of Reading, where the Hugh Sinclair Nutrition Unit thrives under Christine Williams.

This is no detective story: there are no elegantly designed experiments or startling discoveries. It is a salutary warning to nutritionists that scientific progress is made by good experimental design and meticulous attention to detail and not by travelling the world on lecture tours.

Tom Sanders is in the Department of Nutrition \& Dietetics, King's College London, Franklin-Wilkins Building, Stamford Street, London SE1 9NN, UK.

\section{In for the count}

\section{Mathematical Mountaintops: The \\ Five Most Famous Problems of All Time \\ by John Casti \\ Oxford University Press: 2001. 288 pp.}

$£ 19.95, \$ 25$

\section{Simon Singh}

The recent boom in mathematics bestsellers has contributed a great deal towards raising the public profile of the subject. But such books ignore a significant section of potential readers, namely those who have more of a mathematical background than the general reader but who are not professional mathematicians. Such mathematical enthusiasts have no doubt enjoyed some of the popular books, but would really prefer a more technical treatment. This is exactly what John Casti provides in Mathematical Mountaintops. It is neither a textbook nor a pop maths book, rather it is a serious in-depth look at the great problems of mathematics.
Casti has picked "the five most famous problems of all time", and spends 30 to 40 pages describing each one. The problems are Hilbert's tenth problem, the four-colour problem, the continuum hypothesis, the Kepler conjecture and Fermat's last theorem. Each of these has now been solved, so, in addition to outlining the problem, the author is able to explain the solution and recount the story behind it. Four of the problems have been written about extensively elsewhere, but perhaps not with Casti's balance of technical explanation and background narrative.

Casti's remaining problem, the Kepler conjecture, has (to my knowledge) not been written about since the recent announcement that it has been proved, and provides perhaps the most interesting chapter. The problem dates back to 1606, when Johannes Kepler posed a question in a paper for his patron Johann Matthäus Wacker of Wackenfels, Knight Bachelor. Kepler asked, what is the most efficient way to stack spheres so as to minimize the spaces between them? Alternatively, what is the best way to pack oranges in an infinite box? Kepler proposed that the best arrangement was the face-centred cubic lattice, in which every sphere in the first layer is surrounded by six others, and each subsequent layer is built by putting spheres in the dimples of the layer below. This arrangement has a packing efficiency of $74.048 \%$. Grocers, who traditionally stack oranges in this way, suspected that Kepler was right, but it took mathematicians almost four centuries to prove it.

There were some notable milestones along the way. In 1694, Isaac Newton and the Scottish astronomer James Gregory argued about the sphere-kissing problem: what is the maximum number of spheres you can place simultaneously in contact with a central sphere? Newton said that the answer was twelve, which is easily achievable, but Gregory was convinced that it was possible to squeeze in a thirteenth sphere. Newton turned out to be right, but this took 180 years to prove.

The Kepler conjecture was eventually proved in 1998 by Thomas Hales of the 